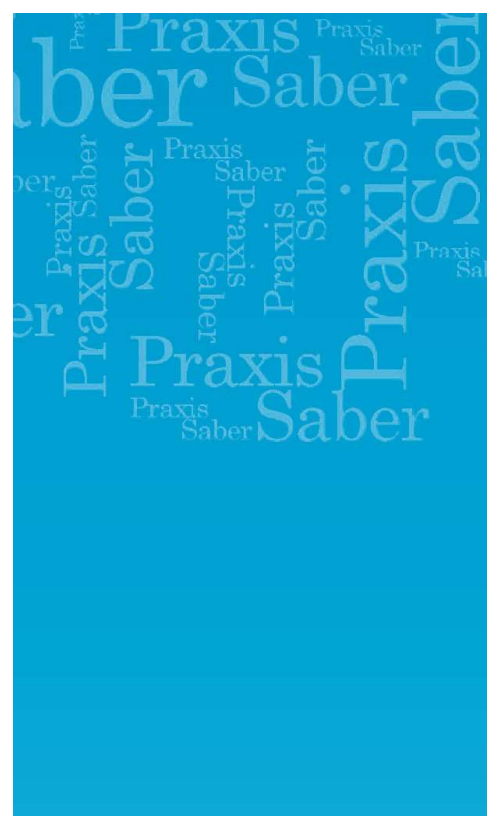

María Teresa Suárez Vaca magiayona@hotmail.com

Estudiante de la Maestría en

Educación

Universidad Pedagógica y

Tecnológica de Colombia

Profesora catedrática y Directora

Jardin Infantil Uptc

Grupo de investigación:

Filosofía, Sociedad y Educación

Articulo de reflexión

Fecha recibido:

20 de septiembre de 2010

Fecha aprobado:

24 de noviembre de 2010

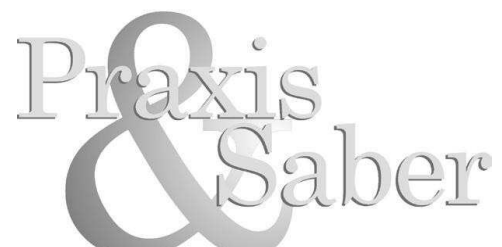

Revista de Investigación y Pedagogía Maestría en Educación. Uptc

\section{LA MAGIA Y UNA NUEVA RELACIÓN PEDAGÓGICA CON LA INFANCIA}

\author{
MAGIC AND A NEW PEDAGOGICAL \\ RELATIONSHIP WITH EARLY CHILDHOOD
}

LA MAGIE ET UN NOUVEAU RAPPORT PEDAGOGIQUE AVEC L'ENFANCE

A MAGIA E SUA RELAÇÃO PEDAGÓGICA COM A INFÂNCIA 
María Teresa Suárez Vaca

\title{
Resumen
}

Fundamentado en la reflexión sobre las prácticas de la autora, a la luz del estudio de literatura sobre la magia y la relación pedagógica, como también sobre trabajos investigativos, incluido su proyecto de grado para la Maestría en Educación, el artículo presenta y desarrolla analíticamente cuatro ideas: la magia en los límites de la ciencia moderna, como construcción cultural que ha retado la realidad y la imaginación; la infancia, como una dinámica del ser humano, vinculada con la curiosidad, la fuerza exploratoria, el atrevimiento, posibilidades de ser y de transformación; el maestro de la infancia en cuanto dinamizador de los procesos cognitivos y de ambientes de aprendizaje, y una nueva manera de entender la relación pedagógica con la infancia, que se plantea a partir del examen crítico de la anterior información.

Palabras clave: Educación preescolar, Pedagogía, Magia.

\begin{abstract}
Based on the reflection about the practices of the author and in the light of the study of literature in relation to magic and pedagogical relationship, as well as several research projects, including her own Master's Degree project in Education, this article analytically presents and develops four ideas: magic at the limits of modern science, as a cultural construction that has challenged reality and imagination; early childhood, as a dynamic process of the human being, linked to curiosity, exploratory power, audacity, possibilities of being and becoming; the early childhood educator as driving force of cognitive processes and learning environments, and finally, a new way to understand pedagogical relationship with preschoolers that arises from the critical examination of the previous information.
\end{abstract}

Key words: Preschool education, pedagogy, magic. 


\section{Résumé}

L'article présente et développe d'une manière analytique quatre idées, en ayant comme fondement la réflexion sur les pratiques de l'auteur, à la lumière de l'étude de la littérature sur la magie et le rapport pédagogique, ainsi que sur les travaux de recherche y compris celui qui fait partie de ses études dans le cadre du Master en Education. Ces quatre idées-là sont : la magie dans les limites de la science moderne, comme une construction culturelle qui a retardé la réalité et l'imagination; l'enfance, comme une dynamique de l'être humain, liée a la curiosité, la force exploratoire, le fait d'oser, des possibilités d'être et de transformation; le maitre de l'enfance en tant que l'acteur de dynamisation des processus cognitives et des environnements d'apprentissage ; et une nouvelle manière de comprendre le rapport pédagogique avec l'enfance, qui se présente `a partir de l'examen critique de l'information précédente.

Mots clés: Education préscolaire, Pédagogie, Magie.

\section{Resumem}

Fundamentado na reflexão sobre as práticas da autora, desde o estudo da literatura sobre a magia e a relação pedagógica como também sobre pesquisas, incluído seu projeto do grado para la Maestria em Educação, o artigo apresenta e desenvolve analíticamente quatro ideias: a magia nos límites da ciência moderna, como uma dinámica do ser humano, ligada com a curiosidade, a força exploratoria, o atrevimento, as posibilidades de ser y de transformação; o maestro da infância em quanto dinamizador dos procesos cognitivos do ambientes de aprendizagem; e uma nova maneira de entender a relação pedagógica com a infancia, que se plantea a partir do examen crítico da anterior informação.

Palavras centrais: Educação pre-escolar, pedagogía, magia 
María Teresa Suárez Vaca

\section{INTRODUCCIÓN}

Este artículo, basado en el estudio de literatura sobre la magia y la relación pedagógica, en la reflexión de la autora sobre sus propias prácticas de magia y de pedagogía infantil, y en su trabajo investigativo para optar el título de Maestría, plantea una nueva manera de entender la relación pedagógica con la infancia: como un encuentro equilibrado entre tres protagonistas: niño, maestro y magia. Inicialmente se hace un recorrido práctico y cultural, a través de la epistemología, que permite reconocer el acercamiento y la estrecha relación que tiene la magia con la ciencia y, por ende, con los métodos de investigación. Para efectos de construir esta nueva relación pedagógica se asume, en la segunda parte, una posición definitoria de la infancia como elemento fundamental, clarificando aspectos determinantes que la conciben como un estado de vida, principio, incertidumbre, transformación, fantasía, lúdica y de relaciones pedagógicas. En la tercera parte, la magia se piensa en clave pedagógica, porque el maestro se constituye en un eje transversal mágico que proyecta encantamiento, misterio e incertidumbre, siendo también un posibilitador de ambientes para el aprendizaje. En la cuarta y última parte, el artículo construye un vínculo relacional entre niño, maestro y magia, en el cual el uso de la magia se convierte en un aporte novedoso para la comprensión y desarrollo del pensamiento y la práctica pedagógica con la infancia.

El más bello sentimiento que uno puede experimentar es sentir misterio. Esta es la fuente de todo arte verdadero, de toda verdadera ciencia. Aquel que nunca ha conocido esta emoción, que no posee el don de maravillarse ni encantarse, más vale que estuviera muerto: sus ojos están cerrados. (Albert Einstein, 1879-1955) 


\section{LA MAGIA EN LA FRONTERA DE LA CIENCIA}

La magia, prestidigitación o ilusionismo es reconocida hoy como la "reina de las artes"; apoyada en historias ocultas y misterios, ha trascendido a través del tiempo, siempre rodeada de ilusiones y fantasías que se hacen realidad, constituyendo un extraño universo donde las leyes naturales se suspenden, un espectáculo de maravillas de la mente, de manos ágiles, de montajes tecnológicos y, sobre todo, de mucha creatividad y conocimiento. Este espectáculo se encuentra en apogeo: se celebran congresos como nunca antes; se convirtió en una atracción para clubes, fiestas y eventos de importancia; existen círculos y asociaciones que fomentan y perfeccionan este arte; el mago ya no es un mito, maneja algo de misterio, pero en esencia, es un artista.

Hacer magia, tiene como intención, básicamente, divertir, ilusionar y transportar la imaginación hacia lo imposible; poder que adquieren los magos por el conocimiento de enigmas y secretos; pero esta noble finalidad actual ha tenido diferentes connotaciones a través de la historia.

Desde tiempos primitivos se reconoce que el hombre tiene como objetivo primordial "sobrevivir"; su mayor esfuerzo estuvo orientado a mantener la existencia; en la medida que conoce su entorno y se defiende en él, puede seguir adelante. Inicialmente, cuando se encuentra con situaciones o fenómenos naturales desconocidos, se forma una visión mágico-religiosa del mundo; de alguna manera, este sentimiento mágico se convirtió en el primer arrojo de tipo experimental para conocer el mundo y sus objetos.

Para Wendy Rydell, "La magia fue la primera religión del hombre; su primera tentativa para comprender y dominar el mundo circundante. Es posible que la magia constituyese la base de los primitivos esfuerzos humanos en los terrenos de la ciencia, la medicina, la tecnología y las artes 
María Teresa Suárez Vaca

creativas" $(1978$, p. 11). Aquí está la base que fundamentó inicialmente la magia: la necesidad de conocer, creer y dominar; una intención clara y unos verdaderos deseos de comprender y explicar fenómenos naturales (físico-químicos, biológicos) y humanos (psicológicos, sociales y culturales), y, con este saber, incidir en ellos, porque a la persona conocedora de estos secretos, para muchos desconocidos, se le atribuían poderes. Aquella persona que estudiaba y descubría fenómenos, se valía de estos saberes para hacer creer a los demás que era un ser supremo y poderoso, para dominarlos y atemorizarlos y convertirse en esencial para la comunidad o tribu. Era el hechicero, el sumo sacerdote, el brujo, el chamán, el vidente y el adivinador del futuro; aquel ser que dirigía mediante la ejecución de rituales mágicos; pero en realidad eran hombres comunes, hombres con poder de conocimiento, sencillamente los más cercanos a la ciencia.

Esto sucedía en todo el mundo. En Caldea surgían astrólogos y numerólogos un poco más avanzados que formulaban una completa cosmología cuasicientífica: las estrellas, los planetas y su influencia sobre el destino humano; trazaban horóscopos y dominaban así en su tierra. Contemporáneamente, en Egipto surge una civilización que combinaba la magia ceremonial y los ritos religiosos; de esta forma, los hechiceros, brujos o magos se mantuvieron durante mucho tiempo junto a los jefes, sacerdotes, faraones y a todos aquellos que gobernaban, siendo muy importantes en su época; esto se ha comprobado en grabados y en papiros encontrados hacia el año 2.000 a. C., donde se plasman juegos de magia que aún se practican; existe evidencia de un dibujo en el muro de una cámara mortuoria de la ciudad de Beni Hasan, el cual representa a dos hombres que manipulan cuencos con una bolita; los jeroglíficos presentan el juego como algo maravilloso y cotidiano; esta sería la primera versión en el antiguo Egipto del famoso juego, común entre los magos, que consiste en encontrar la bolita bajo un tazón (el clásico "dónde está la bolita"). Lorgia (1997) refiere en su libro a Séneca, quien también menciona este juego en las epístolas a Luciano, donde reconoce que es un truco, pero que no revela su secreto puesto que perdería el encanto que produce su efecto.

\section{La ciencia como magia o la magia como ciencia}

Con los diferentes avances tecnológicos y científicos se inicia un nuevo modelo de racionalidad. Morin (1998), citado por Maximiliano Korstanje, aporta los mejores argumentos para establecer nexos entre magia y racionalidad: 
¿Por qué la antropología ha sido tan aberrante a principios de siglo [xx]? Porque los antropólogos estaban convencidos de ser los dueños de la sabiduría y la racionalidad, por el hecho de su perspectiva occidental, y consideraban lo que veían como un mundo arcaico de niños grandes que vivían de manera puramente animista, mística, o neurótica [...]; no se había comprendido que coexistían tanto racionalidad como magia en esas sociedades. Así como no se había visto que había magia en nuestra sociedad al mismo tiempo que racionalidad, e incluso en el interior de nuestra racionalidad (Korstanje, 2009, p. 3).

Esto evidencia el surgimiento científico y racional con base en algunos conocimientos mágicos; pero también es el primer paso para quebrantar estos ideales míticos, mágicos y religiosos que se empiezan a deslegitimar.

Posteriormente, y con base en ese ejercicio de racionalidad, se inicia un nuevo paradigma basado en la observación sistemática, que inaugura la ciencia moderna positivista; esta inicia un enfrentamiento abierto a muchos ritos y fórmulas mágicas y comienza una nueva era fundamentada, observable y científicamente comprobable: "La utilidad, rigurosidad lógica y capacidad de predicción, control de situaciones o hechos naturales permitieron un avance inusitado a ciencias como Biología, Química y Física" (Tamayo, 2009, p. 2) Por tal motivo, este paradigma se impone con firmeza y solidez sobre los saberes míticos no comprobables; "se convirtió en todo un modelo de conocimiento que supone que la realidad está dada y que los hechos que la constituyen se pueden descubrir mediante la aplicación de los métodos científicos" (Tamayo, p. 2).

Ante esta situación la magia pierde fuerza y validez, y su poder y credibilidad se ponen en tela de juicio.

Con su premisa de que la tierra era el centro del universo, la Astrología entró en conflicto con la ciencia de la Astronomía, y la comprensión de que los mapas astrológicos de los Caldeos estaban equivocados. Los conceptos 
María Teresa Suárez Vaca

matemáticos de Euclides y otros chocaron de frente con la numerología. El estudio de la física y las leyes naturales hizo que los descubrimientos científicos sustituyeran las fórmulas mágicas. Elevada a la categoría de ciencia por Hipócrates y otros médicos, la medicina se enfrentó abiertamente a los ritos curanderos de la magia. De modo que en la antigua Grecia se entabló una batalla épica para conquistar el corazón y la mente de los hombres durante las generaciones futuras (Rydell, 1978, p. 23).

Con base en todo esto, y totalmente deslegitimizada, la magia no se rinde, y para sobrevivir se divide abiertamente en dos grandes vertientes, que adquieren fuerza, pero que se alejan rotundamente entre sí: la magia negra, relacionada con hechicería, culto a espíritus malignos, maldiciones y poder, y la prestidigitación o ilusionismo; ésta es realizada como un arte escénico, como un espectáculo para divertir a un público, por magos o ilusionistas que desarrollan una maravillosa habilidad para la ejecución de juegos de manos, y sin dejar de ser un misterio progresa día tras día, valiéndose de la ciencia para su evolución.

\section{La magia como construcción científica en un paradigma positivista}

Para ilustrar la relación magia-ciencia se presenta un caso muy mágico y llamativo: en el templo de la estatua de Isis, la "gran maga", en Egipto, cuando se encendía fuego sobre el altar, la estatua comenzaba a verter vino, como una forma de adoración... ¿Magia? o ¿ciencia? Gran misterio adjudicado por mucho tiempo a la magia y al poder supremo de los sumos sacerdotes; pero todo se ha develado, y con el tiempo se comprende que lo que había era un sistema rudimentario automático: un tubo oculto dentro de la estatua estaba conectado hábilmente a un depósito de vino; al encender el fuego se dilataba el aire, que pasaba a otra cavidad bajo el recipiente y dicha presión impulsaba el vino por el tubo y finalmente, de manera milagrosa, se vertía sobre el altar; cuando el fuego se apagaba el aire se enfriaba, bajaba la presión y el fluir del vino cesaba. Esto lo explicó el ingeniero y matemático Griego Hero de Alejandría, un científico estudioso que desentrañó muchas leyes físicas utilizadas en estas ilusiones mágicas... Arte, claramente cimentado en acciones positivistas de causa y efecto; fundamentado en leyes naturales y científicas. Son muchos los efectos mágicos que han hecho historia y que seguirán 
sorprendiendo al mundo, y que, al ser descifrados, son genialidades de la ciencia, pero utilizadas para ilusionar.

La forma de trabajo para muchos magos fue el método hipotético deductivo expuesto como "un método puesto a prueba con la experimentación, que modifica intencionalmente los elementos de un fenómeno para confirmar una supuesta relación" (Tamayo, 2009, p. 2). En 1584, Reinald Scot publicó un tratado de ilusionismo titulado The Discovery of Witchcraft (El descubrimiento de la brujería), donde se explican muchos juegos de ilusionismo que se basan en los conocimientos científicos, y son producto de un trabajo riguroso, ingenioso y creativo; en el fondo, la intención no solo era develar secretos, sino disociar totalmente el arte de la brujería; este libro abre las puertas o el camino para una serie de manuales sobre ilusionismo.

La situación clarifica y evidencia un sistema de investigación científica positivista para controlar y predecir lo inexplicable, lo cual permitió hacer generalizaciones para muchos proyectos mágicos posteriores; los libros de ilusionismo aceptan abiertamente la realidad y el truco de los juegos; una realidad accesible solo mediante la experiencia y el conocimiento. El sujeto y el objeto son independientes; el mago descubre y conoce el secreto para hacer determinada acción, es decir, tiene acceso a una realidad mediante los sentidos, la razón y los instrumentos elegidos; acepta el conocimiento científico como válido, y establece la posibilidad de generalización, buscando leyes independientes de tiempo y espacio; por lo tanto, se pueden instituir las causas que preceden o se dan simultáneamente con los objetos; en estos libros se establecen claramente los procedimientos de ejecución y las relaciones constantes con los hechos, para comprender los efectos mágicos o trucos.

\section{La magia como construcción y práctica cultural}

Hablar de magia como fenómeno cultural o como una forma diferente a la ciencia invita a vislumbrarla como un arte de construcción social, donde se determinan los valores del mago y del contexto, la técnica y la relación coherente entre todos. La prestidigitación o el ilusionismo, como arte, como espectáculo y no como acciones técnicas, se ubica en un paradigma naturalista; allí la naturaleza de la realidad es múltiple; hay una relación constante e importante con los

sujetos espectadores; su relación es inseparable; debe haber una interacción motivante y es dependiente del contexto. 
María Teresa Suárez Vaca

Los objetos artísticos poseen -en este sentido- una particular dimensión ontológica y cognoscitiva, adquiriendo el estatuto de huella antropológica, de síntoma histórico-cultural de determinadas sensibilidades propias de la comunidad que las realizó. En las producciones artísticas -con sus resonancias filosóficas y espirituales- es posible leer la sensibilidad de una época o, si se quiere, la condición psicológica de la humanidad en una situación dada (Rocca, 2006, p. 48).

Se evidencia la importancia del contexto en el trabajo artístico y cómo la cultura influye en sus producciones y propuestas creativas. El mundo de la magia es evidentemente influenciado por las modas, los avances técnicos y las características sociales del lugar donde se producen.

De forma concluyente, el arte del ilusionismo trasciende a un ámbito social y cultural, y exige nuevas formas y criterios de racionalidad para construir conocimientos. El arte debe evolucionar según el contexto tiempo-espacio, para formarse como una disciplina definida pero cambiante. Por lo tanto, la magia ha avanzado a través de la historia según las comunidades y el contexto, y en la medida que se han develado secretos se propugna crear nuevas ilusiones con base en esos saberes; otro aspecto influyente es el avance tecnológico, que ha permitido hacer propuestas nuevas muy creativas.

Toulmin (1977) expresa que siempre surgirán personas innovadoras y creativas con nuevas propuestas de cambio que entrarán a competir intelectual y, en este caso, artísticamente con las ya establecidas y aceptadas, las cuales responderán a las exigencias del medio. En el caso de la magia, la diversa categorización y las competencias locales e internacionales invitan a crear e innovar permanentemente. Existen comunidades mágicas especializadas en áreas específicas, como cartomagia, grandes ilusiones, close up, etc., que permanentemente estudian y exigen cambios en el arte. Para Toulmin (1977), juegan un papel importante las comunidades conceptuales, que con un juicio crítico presionan al cambio; en este caso particular se hace referencia a las agremiaciones de magia, los jurados y el público en general, quienes se constituyen en ojos críticos que evalúan y juzgan a los nuevos ilusionistas, exigiéndoles reconocer los problemas o necesidades de cambio; con base en esto se elaboran y surgen nuevas propuestas artísticas creativas e innovadoras, permitiendo así la evolución constante de la magia. 
Finalmente, este recorrido histórico y cultural a través de la epistemología permite reconocer el acercamiento y la estrecha relación que tiene la magia con la ciencia y, por ende, con los métodos de investigación. Después de todo, cabe la ilusión de seguir trabajando con base en la historicidad y en nuevos criterios epistemológicos que en un momento dado pueden fundamentar la relación entre magia, sujetos, conocimiento y, por ende, pedagogía.

\section{LA INFANCIA Y SU RELACIÓN CON LA PEDAGOGÍA}

Son muchas las concepciones que intentan definir la infancia, y existen producciones históricas de tipo psicológico, antropológico y sociológico que dan cuenta de teorías universales relacionadas con el tema y que se constituyen en fundamentos conceptuales para las diferentes elaboraciones y propuestas pedagógicas relacionadas con la formación y el desarrollo de los niños. El historiador francés Philippe Ariès, con base en sus estudios, enuncia que la infancia es un "invento de la modernidad", cuando se le otorga un lugar particular en tiempo y espacio, un estatus diferenciado frente a los adultos. Por lo tanto, surgen nuevas estructuras sociales y culturales que transforman su sentido y atención: se diseñan políticas públicas, normativas y académicas, estrategias de crianza, juguetes y material especializado solo para niños. Por lo tanto, la infancia se posiciona con ímpetu y fuerza en la modernidad, producto de una construcción cultural, pero en muchos casos es caracterizada, infortunadamente, por posturas negativas y censurables; como expresan Pineau y Marcelo, "la construcción de su especificidad, diferenciándola de la adultez, es incompletud" (2005, p. 35), es decir, la infancia es fragmentaria, débil, que precisa ser educada o formada.

Para efectos de esta relación pedagógica es importante asumir una posición definitoria de la infancia, porque es un elemento fundamental en la clave pedagógica y en su vínculo con la magia. Se clarifican aspectos determinantes partiendo de que infancia no es edad o etapa de desarrollo, sino un estado de vida, principio, incertidumbre, transformación, fantasía, lúdica y de relaciones pedagógicas.

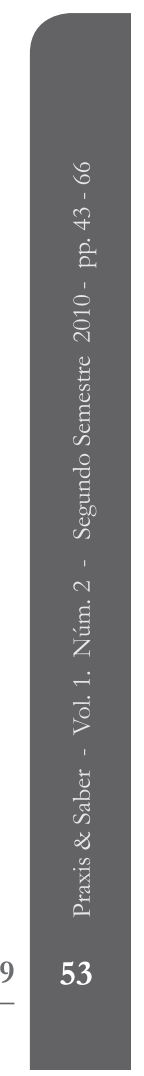


María Teresa Suárez Vaca

\section{Infancia y vitalidad}

Pensar la infancia en esta relación es vital, y es importante el reconocimiento como sujeto vivo; infancia es un sentir, es fuerza, aliento, energía, juego, atrevimiento, incertidumbre, amor, necesidad, llanto..., es vida; definitivamente, no hace referencia a un estadio de desarrollo establecido, ni a los niveles promulgados por el Ministerio de Educación, no es solo el sujeto/ objeto que se debe formar. Infancia es el inicio de la vida, es el principio del mundo, la base de la historia, y se constituye en la esencia del futuro; en palabras de Walter Kohan, es:

Un estado de atención, una forma de sensibilidad, una manera de experimentar el mundo y de relacionarse con quienes lo habitamos. La infancia no es cuestión de medida y de tamaño, de cantidad, sino que es un estado de principio, un inicio perpetuo, una percepción sin antecedentes de aquello que nos hace ser lo que somos. Es una fuerza vital, un estilo (2009, p. 6).

\section{Infancia: pregunta y creación}

Es evidente que la infancia está rodeada de preguntas, inquietudes e incertidumbres, porque se quiere y se debe construir a sí mismo; es el estado perfecto para la creación, donde todo es posible e imaginable; por lo tanto, es "un estado mágico"; sí, mágico porque es un mundo de fantasía y esperanza creadora donde todo puede ser posible, es una ventana que abre la posibilidad a hechos inadmisibles, es el deseo de ser y la ilusión que permite construir su propia realidad. Entonces, infancia es un estado de construcción, es la condición para aprender; sus ausencias de saber, o la antes mencionada incompletud, no son debilidad; por el contrario, se constituye en la fuerza y el estado natural para aprender y constituirse. "Lo que se presenta como una ausencia de voz es también la condición para adquirirla" (Kohan, 2009, p. 9).

\section{Infancia y transformación}

A través del tiempo se ha tenido conciencia de que la formación que reciba el niño es la base para lo que será en un futuro, y para muchos la infancia es material raso, permeable y voluble, materia para moldear sueños adultos (políticos, sociales, éticos, estéticos, corporales 
y culturales). Walter Kohan recuerda que "a partir del libro II: Sócrates y sus interlocutores perciben que es inevitable ocuparse de y preocuparse con la educación de la infancia [...]. Ocuparse de la educación de la infancia es el camino inevitable si queremos una polis más bella, justa y mejor" (Kohan, pp. 14-15); aquí se reitera la condición del niño como un ser listo y necesitado de formación y nomina la "educación" como el instrumento para formar; pero detrás de todo hay intenciones políticas y sociales, puesto que se considera la educación inicial como una estrategia de preparación y transformación del futuro ciudadano.

Pero ¿cuáles son los criterios de formación?, ¿̇on los sueños de los formadores?, ¿estamos siendo partícipes de la fabricación y no estamos cumpliendo la misión de permitir que los niños construyan su propia formación y "se hagan obra de sí mismo", como señaló Pestalozzi (1797)? La educación no debe ser una forma de producción o de clonación personal; se debe salir de esa emoción egocéntrica que conduce a una educación conservadora obsoleta y que pretende, de alguna forma, perpetuar a los maestros sin pensar en los niños, a quienes se sacrifica antes de ser, se les vendan los ojos al conocimiento, educándolos en la repetición de textos y situaciones incoherentes con la vida, con sus intereses, con sus ilusiones.

Sin embargo, es importante reconocer que la educación es necesaria, se necesita como oportunidad para crecer. Pero para desarrollar seres humanos autónomos, libres, propositivos y creativos se precisa brindar o recibir propuestas de conocimientos o acciones que enriquezcan y permitan obtener un desarrollo de habilidades para desenvolverse en la vida; "El niño necesita, pues, ser acogido; necesita que haya adultos que le ayuden a estabilizar progresivamente las capacidades mentales que le ayudarán a vivir en el mundo" (Meirieu, 1998, p. 23). Por lo tanto, inicialmente, y por algún tiempo, es importante el acompañamiento directo, el ejemplo de vida, el encuentro con maestros, con el mundo; todos en conjunto hacemos historia que de alguna forma fundamenta el destino de los niños.

\section{Infancia, magia y fantasía}

Para comprender la relación de la magia con la infancia, valdría la pena revisar el siguiente paralelo con la literatura: 
María Teresa Suárez Vaca

Un cuento de hadas sobre la página impresa excita la curiosidad del niño y amplía su imaginación. Cuando este es bien leído o relatado por un buen narrador, se añade un elemento dramático. La magia agrega una dimensión adicional. Un truco mágico bien presentado es un cuento de hadas traído a la vida. El mago es un narrador de historias, y las maravillas que relata parecen suceder. Esta es la razón por la cual los niños se sienten fascinados por la magia. [...] Si usted puede hacer aunque sea un truco realmente mágico, usted podrá disponer de la atención instantánea de cualquier niño. Si puede ejecutar varios, es usted supermán, Merlín y el hada madrina en una sola persona. Es una forma certera de hacer amistad con los niños y de ejercer influencia sobre ellos (Rawson, 1987, p. 13).

Cuando se actúa para niños se cuenta con un público entusiasta y bien dispuesto, demasiado servicial, "son pequeños exploradores" que representan el público más ruidoso, atento, espontáneo y soñador del mundo. Kohan manifiesta que "la infancia, a diferencia de la adultez, es para Heráclito un modo de enfrentar con más oportunidad las contradicciones que hacen parte de lo humano: ver lo no vivible, pensar lo no pensable, esperar lo inesperable" (2009, fragmento 18). Los niños creen en la magia y aceptan a primera vista que el mago es un creador de maravillas; por lo tanto, desean profundamente que esta sea real.

Esta capacidad imaginativa y de sueños es la que alimenta la magia y hace parte fundamental de la infancia; por lo tanto, defender la imaginación y la fantasía se puede plantear como una maniobra para la formación integral de los niños. Bruno Bettelheim, en su libro Psicoanálisis de los cuentos de hadas, manifiesta la importancia que tiene el mundo mágico de los cuentos en la formación de la personalidad, y cómo los niños necesitan magia y fantasía para su desarrollo; sus planteamientos se basan en el gusto por los cuentos e historias fantásticas y en su estudio desde el psicoanálisis. Bettelheim expresa: "Para que una historia mantenga de verdad la atención del niño, ha de divertirle y excitar su curiosidad. Pero para enriquecer su vida ha de estimular su imaginación, ayudarle a desarrollar su intelecto y a clarificar sus emociones; ha de estar de acuerdo con sus ansiedades y aspiraciones; hacerle reconocer plenamente sus dificultades, al mismo tiempo que le sugiere soluciones a los problemas que le inquietan" (1983, p. 11), es decir, que las relaciones, el ambiente y las acciones que se desarrollan con los niños 
deben ser estimulantes, divertidas, agradables y, ¿por qué no?, mágicas; pero deben tener una intencionalidad clara y bien estructurada.

\section{Infancia y lúdica}

La relación pedagógica mediada por el arte de la magia se constituye en un momento de alegría, de entusiasmo, dado que la magia es, de alguna manera, parte del lenguaje natural y lúdico de la infancia, porque, ante todo, el niño es juego. El doctor Raimundo Dinello manifiesta que el proceso creador y expresivo necesita estar enmarcado en la alegría y la satisfacción personal, y considera que "es importante la tonalidad lúdica porque asocia intensamente al imaginario y éste es vía de aprendizaje de nuevos conocimientos" (2006, p. 27). De acuerdo con esta afirmación, la lúdica se percibe, ante todo, como un sentir que conlleva acciones por gusto y por placer, se trata de dar fuerza a los intereses y no solo a las necesidades, como expresa Dinello: "Los sujetos se afirman con el placer de descubrir, experimentar y elaborar conclusiones; en marcado contraste cuando se hacen ejercicios partiendo de la experiencia del docente o manuales que indican un derrotero didáctico" (2006, p. 29); de esta forma se corrobora que el sentimiento lúdico y actitudinal provoca efectos positivos en las acciones y en el aprendizaje.

\section{Infancia y relación pedagógica}

Este apartado se fundamenta en la importancia que tiene la educación y en cómo se constituye en un elemento necesario para la vida, porque es el encuentro con la realidad de un mundo ya establecido, de su historia, normas y espacios; es decir, una entrada a la convivencia comunitaria. El mundo recibe al niño completamente despojado, y por eso la actitud y el encuentro educativo con los padres, los maestros, la sociedad y su historia son determinantes, ya que se construye un vínculo de coexistencia; como dice Meirieu, "Educar es, pues, introducir a un universo cultural, un universo en el que los hombres han conseguido amansar hasta cierto punto la pasión y la muerte, la angustia ante el infinito, el terror ante las propias obras, la terrible necesidad y la inmensa dificultad de vivir juntos" (1998, p. 25).

La construcción personal en los niños, a pesar de su propia fuerza, no siempre se da por sí misma; requiere de interacciones al servicio de la autodefinición; por lo tanto, infancia también es "relación" que busca y permite encontrar un sentido a la vida, poco a poco descubre o 
María Teresa Suárez Vaca

construye estrategias para comprenderse mejor y comprender a los otros, para interactuar y así vivir satisfactoriamente y con identidad; pero "la identidad no debe ser comprendida tan sólo como una aspiración hacia la individualidad, sino que abarca también, gracias a la solidaridad, una aspiración hacia una emancipación común y una autorrealización" (Reinert, 1984, p. 66), es decir, que el proceso de relación o interacción tiene sentido para el crecimiento social, cultural y político, pero ante todo debe estar fundamentado en el respeto a la identidad, donde el niño tiene la capacidad de constituirse a sí mismo, a pesar de estar inmerso en dicha relación como parte de su destino humano.

La certeza que se configura es que este vínculo pedagógico se constituye en un momento de construcción o de partida que abre las puertas al conocimiento, un "pase mágico" externo que hace posible cualquier creación; tal como lo expresa Violeta Núñez, estableciendo relaciones con la educación, "el vínculo educativo puede jugar, si se juega bien, como una plataforma de lanzamiento a lo nuevo, a lo por-venir; si se instala en la paradoja de sujetar para permitir que cada cual se lance a sus propias búsquedas" (2003, p. 39). Es en definitiva un momento de motivación y acompañamiento que invita a producir; no es dar para reproducir, es cuestionar y propiciar el deseo de saber.

\section{PENSAR LA MAGIA EN CLAVE PEDAGÓGICA}

\section{La magia en diversos contextos}

Con el transcurrir del tiempo y con tantos avances científicos, la magia, o el arte del ilusionismo, ha evolucionado, pretendiendo alejarse al máximo de la posible relación con la brujería, y se piensa como espectáculo; pero también, teniendo en cuenta las necesidades y los diferentes contextos, surgen nuevas propuestas de trabajo e investigación para utilizar este arte y encontrarle nuevas funcionalidades, diferentes a la de divertir, como se ilustra con los siguientes casos.

En Medellín, Colombia, actualmente existe una experiencia de trabajos de integración social para jóvenes de las comunas a través de talleres mágicos con el mago Makandal. También 
hay un gremio de magos en diferentes partes del mundo que utilizan la magia en Pediatría para tratar las enfermedades de los niños o para llevarles momentos de ilusión y felicidad mientras se encuentran hospitalizados; por ejemplo, en Colombia está el caso de Jairo Ortega, el Dr. Magic, médico cirujano de profesión, y mago por pasión, quien organiza frecuentemente actividades mágicas en hospitales y centros pediátricos (http://www.eltiempo.com/archivo/ documento/MAM-686232). Adrián Guerrero González, en Buenos Aires, Argentina, utiliza la prestidigitación (trucos de magia) como ayuda visual para evangelizar. San Juan Bosco también utilizó la magia para enseñar o catequizar, y ordenado como sacerdote descubrió que al utilizar sus habilidades de mago y malabarista podía predicar la palabra de Dios; sus prodigios mágicos fueron destacados por los pobladores y por tal motivo se le considera el patrono de los magos. La Fundación Abracadabra, de magos solidarios en España, es una ONG que recorre centros especiales y enseña a niños con síndrome de Down, a la vez que adelanta estudios particulares, como "Magia y terapia grupal: principios comunicacionales para producir cambios cognitivos" (www.fundacionabracadabra.org/).

En la Salle International Graduate School, en Madrid, España, existe un curso de capacitación docente que ofrece "ilusionismo y pedagogía: la magia como instrumento para la educación" (posgrados@lasallecampus.es). Francisco Ramón Ballesteros Rueda trabaja "La magia en la escuela...", específicamente en la clase de educación física (CEIP Sierra Arana, de Iznalloz, provincia de Granada, España). Otra experiencia pedagógica, de Ferran Homar en el CEIP Jaume I de Pineda de Mar (Barcelona, España), enseña magia para el desarrollo de habilidades motrices.

Las tres últimas experiencias expuestas evidencian el uso de la magia en la educación, pero solo como elemento didáctico, a diferencia de este proyecto, que propone el arte de la magia como elemento dinamizador en la construcción de una relación pedagógica con la infancia, tras demostrar que la magia es una forma para interactuar pedagógicamente con la infancia, para desarrollar capacidades especiales y construir nuevas formas de aprendizaje a través de experiencias dinámicas evolutivas e interactivas, es decir, que se puede establecer una relación mágico-pedagógica para construir conocimiento entre niños, maestro y magia. 
María Teresa Suárez Vaca

\section{El maestro: eje transversal de la relación pedagógica}

El maestro debe proyectar encantamiento a sus alumnos, y, en concordancia con Paulo Freire, debe adquirir seguridad y competencia profesional: "el profesor que no lleve en serio su formación, que no estudie, que no se esfuerce para estar a la altura de su tarea, no tiene fuerza moral para coordinar las actividades de su clase" (Freire, 1999, p. 88). Por lo tanto, el maestro se debe constituir a sí mismo con ojos críticos con base en el estudio y la coherencia práctica; es un ser inacabado en su formación.

Un mago virtuoso se prepara con dedicación y entereza para buscar su mejor presentación y atrapar al público, por lo tanto, primero se constituye a sí mismo, estudia, ensaya; investiga, ensaya; corrige, ensaya; crea y, finalmente, se presenta; pero con el compromiso de repetir cíclicamente el proceso preparador de estudio y ensayos; porque ser mago es también un proceso inacabado; de esta forma se desarrollan habilidades y destrezas que le permiten desempeñarse como prestidigitador o ilusionista, pero esto solamente se logra con preparación y estudio pasional por el arte. Cuando las personas se desempeñan en sus pasiones viven felices, pero también viven con esmero y responsabilidad, no hay horarios para aprender o crecer, y tampoco se perciben obligaciones de cumplimiento; por el contrario, se sienten exigencias personales que en últimas son las motivaciones que buscan y logran nuevas construcciones creativas y la perfección en los actos.

\section{Proyectar encantamiento, misterio e incertidumbre}

El maestro se debe pensar más allá de un simple reproductor de saberes; también debe buscar la capacidad de asombro por medio de elementos comunicativos que atrapen. Por lo tanto, la coherencia entre el gesto, el movimiento y la palabra es fundamental, porque demuestra actitud y seguridad, que en el docente constituyen un elemento clave para relacionarse con los niños; a través de ellas se revela todo: el saber, la inquietud, los sueños y las intenciones. Un buen mago va más allá del simple truco, busca pasar por el misterio y llegar a la ilusión; porque la fuerza no está solo en el truco, está en todo lo que le rodea, en su forma de presentación, los gestos de asombro y poder, las palabras precisas, claras, inspiradoras y mágicas, que hechizan y transportan a un mundo fantástico; los movimientos limpios sin trampas a la vista, claros y acompañados de pases mágicos poderosos; la seguridad de ser y de sentirse "mago", de 
producir fantasías. La pretensión del mago es tener poderes mágicos, y se debe estar seguro: "el mago es un actor que finge ser un mago y como cualquier actor adquiere la confianza y la destreza que necesita por medio de la práctica y el ensayo. [...] Dado que el mago es un actor, el truco de magia es una pieza dramática corta, y las instrucciones para hacer el truco son su guión de actuar" (anónimo, s. f., p. 15-16). Uno de los grandes secretos de un buen mago es la verdadera actuación: entre los magos profesionales hay una máxima muy antigua y cierta que afirma: "No se trata de qué se hace, sino de cómo lo hace"; por lo tanto, cuando solo se presenta un juego o truco, simplemente se ha propuesto un "acertijo" que, presentado de manera adecuada, podría haberse transformado en una hazaña con apariencia de verdadera magia y, sin duda, mucho más interesante de presenciar. La presentación dramática es la que añade el interés, el suspenso y el humor que hacen divertida la magia. Todos estos elementos, en su conjunto, operan encantamiento en la infancia.

\section{El maestro posibilitador de ambientes de aprendizaje a través de la magia}

El maestro debe preparar ambientes para el aprendizaje acordes con las necesidades e intereses de sus alumnos, evitar clases desgastadas y aburridas, preparar momentos inolvidables para la infancia, utilizar elementos motivantes y sugestivos que cumplan con su función. El acto de magia debe ser pensado con base en su público; en especial, cuando de niños se trata hay que preparar juegos fantásticos, con historias, implementos y efectos llamativos y avasalladores, para nunca olvidar.

Por su parte, el maestro debe ser el causante del gusto, de las ansias de saber y de descubrir significados; su labor no es la de transferir, inyectar conocimientos o dar información; debe ser un promotor de deseo. "La paradoja del deseo se debe, en efecto, a que su objeto debe ser a la vez conocido y desconocido, es preciso adivinar sus formas, entrever el secreto, pero debe permanecer escondido y el misterio no debe ser develado" (Meirieu, 2009, p. 108); para muchos autores es diseñar una situación problema, donde el saber no se da como algo cierto, como diría Paulo Freire, no es el acto de depositar conocimiento, es problematizar para desafiar; es crear un enigma o, más exactamente, "hacer saber un enigma: decir o enseñar lo suficiente a fin de que se entrevea el interés de lo que se dice, así como su riqueza, y callarse a tiempo para despertar el interés por el descubrimiento" (Meirieu, 2009, p. 108). Es una manera de crear fisuras y dudas, porque hay que perder la certeza de lo dado como real, por lo tanto es 
María Teresa Suárez Vaca

promover sujetos capaces de recrear y transformar sus propias realidades, asumiendo nuevos retos.

Stela Quintar refiere que "el sentido de la educación es el de promover el deseo de saber en la conciencia de sí y del mundo, para actuar en él, autónoma-instrumentada y transformativamente, es decir, aprehender en la conciencia de nuestra propia existencia material, des-naturalizando lo dado como natural" (2006, p. 45). En la conciencia de sí se reconocen las emociones con las que se aprende, y de esta forma nos damos cuenta de qué, por qué y para qué aprendemos; es decir, la autorreferencia, que permite definir una posición, ya sea la de permanecer, de transformarnos o de transformar, en libertad con conciencia y asumiendo una postura en lo subjetivo y en lo colectivo; esta es la verdadera motivación para aprender "el deseo intencionado de saber".

El buen mago juega con la incertidumbre, con lo no dado como cierto; proyecta otras realidades, por lo tanto, es un generador de inquietudes; él no enseña, deja sembradas la duda y la curiosidad de querer saber; por lo tanto, el mago es un promotor de conocimiento porque, como expresa Freire, "Si no fuera por la curiosidad no conoceríamos. La curiosidad nos empuja, nos lleva a develar la realidad través de la acción" (2003, p. 22). A través de la magia se invita a investigar, pues es una constante situación problemática que promueve y crea posibilidades, donde el niño tiene que movilizar aproximaciones, lanzar hipótesis; es un juego que rompe con la racionalidad y mueve la emoción; el mago sorprende, no da respuesta y no da explicación, por lo tanto, es un reto para la razón, los magos vivimos gracias a las incertidumbres de la gente. El mago Richard Sarmiento, director de la Escuela de Artes Mágicas de Bogotá, lo expresa así: "La magia comienza cuando la razón termina". Para que sea verdadera magia hay que dejar en la pregunta; de lo contrario puede haber frustración, cuando se expone lo real; los niños quieren ser ilusionados, necesitan magia, porque es parte de su naturaleza. 


\section{UNA NUEVA RELACIÓN PEDAGÓGICA CON LA INFANCIA}

La construcción de una nueva relación pedagógica con la infancia parte de reconocer que la labor educativa es ante todo un encuentro. La relación pedagógica se concibe como un vínculo, un tejido que se construye; es decir, no es una simple intervención o una intromisión para enseñar, para educar; tampoco es el llamado acto educativo de enseñar, de transmitir conocimientos, de desarrollar habilidades o competencias. La relación es una conexión recíproca donde se produce una transformación de todas sus partes; la relación se basa inicialmente en el reconocimiento y el respeto por los sujetos (maestro y alumnos), por el poder que tiene cada uno de "ser", de constituirse por sí mismo en libertad y autonomía.

La pregunta reflexivo-problematizadora se convierte en esta relación, de acuerdo con Quintar, en "un instrumento que abre el campo de la co-emoción, un instrumento comunicacional de apertura al diálogo, a lo conocido para re-conocerlo" (2006, p. 48). Se refiere este autor a la pregunta de sentido, que invita a mirar, para encontrar aquello que parametraliza nuestras creencias "que ponen al sujeto en con-tacto consigo mismo, abriendo/se, indagando/se en la vida misma, desde lo pensado a lo impensado, deteniéndose en cada certeza para preguntarse por qué es certeza, qué la constituye como tal" (Quintar, p. 48); coincide así con Freire, Gramci, Foucault, Gadamer y Derrida en el constante cuestionamiento centrado en la problematización de lo dado como natural, para provocar el deseo de saber. La situación problematizadora es la constante en el mundo de la magia, porque se vive en medio de lo irreal, donde todo puede ser posible y no hay certeza de nada; la pregunta constante rompe lo sabido para buscar con gusto y placer lo no sabido; entonces el aprender en medio de ilusiones se constituye en un espacio gustoso y de deseo potencial por aprender, lo cual es una ganancia; no solo es tener información, sino es crear apetito de aprendizaje y comprensión por lo desconocido. Esta relación pedagógica mágica se podría adherir al enfoque didáctico crítico y no parametral como una alternativa que tiene como constante la ruptura y deconstrucción de parámetros, que invita a expandir las alas para promover seres autónomos, creativos y libertarios.

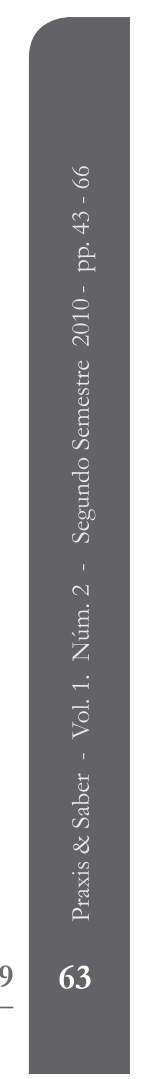


María Teresa Suárez Vaca

La magia en el aula rompe con las lógicas, y en sus manos se hace posible lo increíble, lo no dado como cierto, creando incertidumbres y abriendo la posibilidad de encontrar nuevas verdades en medio de otras lógicas. El reto de la relación pedagógica está en plantear situaciones que provoquen ansias de saber, en motivar aprendizajes a través de las propias búsquedas, no de un simple entregar el saber confirmado como cierto, como última palabra; la relación busca provocar; Violeta Núñez la compara con una joya cuyo brillo es entrevisto, atrayente, motivante, "donde el educador apenas hace entrever el brillo del tesoro de las generaciones. El educador que acepta el reto de establecer un vínculo educativo da el tiempo para aprehender algo de lo que está en espera, de lo que desde el comienzo de los tiempos del hombre nos aguarda a cada uno" (2003, p. 39).

La misma Violeta Núñez plantea en un estudio cómo se ha configurado el vínculo educativo a través de la historia; parte del triángulo Herbartiano, que esquematiza el trabajo educativo compuesto por tres elementos: el sujeto de la educación, el agente de la educación y los contenidos de la educación; también analiza distintos discursos en diferentes momentos históricos: Sócrates, Comenio, Vives, Alain, donde encuentra elementos que marcan la posibilidad de establecer lo que ella llama "vínculo educativo"; expresa como gran descubrimiento que "el vínculo educativo no es del orden de lo estable, no es algo que se establezca de una vez y para siempre entre un agente y un sujeto de la educación. Bien por el contrario, se trata de un instante fugaz, tal vez solo una mirada, pero que deja su marca" (Núñez, p. 38). Por lo tanto, esta relación es una conexión fundamental que deja huella en los sujetos, en este caso, en dos de sus protagonistas fundamentales: maestro y alumno; que descarta por completo que el vínculo sea solo la parte técnica de transmisión de conocimientos, y que, por el contrario, destaca la virtud de la interacción como iguales.

De otra parte, Gerd Bodo Reinert manifiesta que la interacción pedagógica es un aspecto de la acción del pedagogo práctico, la cual incluye corrientes de participación recíprocas entre algunas personas, y considera que "la meta de la interacción pedagógica consiste en crear espacios de juego para la acción, los que promueven la identidad balanceada del yo" (1984, p. 64); así, la identidad del docente es la base fundamental para la interacción con el otro; maestro y alumno son pilares fundamentales de la relación pedagógica; se reafirma, en consecuencia, la importancia del sujeto y la del respeto por el otro, y se agrega un elemento que es el diseño de espacios para la acción. 


\section{REFERENCIAS}

ANónimo (s.f.). La última palabra de la magia y del ocultismo. Buenos Aires: Casa Editorial Domingo Ferrari.

Bethelheim, B. (1983). Psicoanálisis de los cuentos de hadas. Barcelona: Grijalbo.

CARR, S. K. (1988). Teoría crítica de la enseñanza. Barcelona: Edit Martínez Roca.

DinelLo, R. (2006). "Pedagogía de la expresión ludocreativa". Revista Internacional Magisterio, Educación y Pedagogía, N. ${ }^{\circ}$ 19, pp. 27-32.

Freire, P. (1993). Pedagogía de la esperanza. México: Siglo Veintiuno.

Freire, P. (1999). Pedagogía de la autonomía. España: Siglo Veintiuno.

Freire, P. (2003). El grito manso. Buenos Aires: Siglo Veintiuno.

Hum, B. S. (2001). Esquina mágica. [En línea] Recuperado el 16 de julio de 2010 de www. esquinamágica.com.

Kohan, W. (2009). Infancia y filosofía. México D.F.: Progreso.

Korstanje, M. U. (2009). "Magia y estadística. Rituales sociales contra la incertidumbre". Aposta, Revista de Ciencias Sociales, Universidad de Palermo, Argentina. N. ${ }^{\circ}$ 41. [En línea]. Recuperado el 2 de julio de 2010 de http://www.apostadigital.com/revistav3/ hemeroteca/maxi2.

Lorgia, G. (1997). El arte de la magia. Bogotá: Gamma. 
María Teresa Suárez Vaca

MeIRIEU, P. (1998): Frankenstein educador. Barcelona: Laertes.

Meirieu, P. (2004). En la escuela de hoy. Barcelona: Octaedro.

Meirieu, P. (2009). Aprender sí, pero ¿̇cómo? Barcelona: Octaedro.

NúÑEz, V. (2003). Reinventar el vínculo educativo: aportaciones de la pedagogía social y del psicoanálisis. Barcelona: Gedisa.

Pineau, P. y Marcelo, D. I. (2005). La escuela como máquina de educar. Buenos Aires: Paidós Cuestiones de Educación.

Quintar, E. B. (2006). La enseñanza como puente de vida. México: Pensamiento y Cultura.

Rawson, C. (1978). El Gran Merlini. Cómo divertir a los niños con magia que usted puede hacer. México: Editorial Diana.

REINERT, G.-B. (1984). "La interacción pedagógica como aspecto de la acción del pedagogo práctico". En: EDUCACIÓN Collección semestral de aportaciones alemanas recientes en las ciencias pedagógicas. vol. 29, pp. 62-85.

RoccA, V. (2006). "El giro estético de la epistemología. La ficción como conocimiento, subjetividad y texto". Revista AISTHESIS, N. ${ }^{\circ} 39$, pp. 45-61 [en línea]. INSTITUTO DE ESTÉTICA DE LA UNIVERSIDAD CATÓLICA DE CHILE. Recuperado el 18 de julio de 2010 de: http://www.puc.cl/estetica/html/revista/pdf/Adolfo_Vssquez.pdf

RydeLL, W. (1978). El gran libro de la magia. Barcelona: Mundo Actual Ediciones.

Tamayo, A. (2009). Fundamentos epistemológicos de la enseñanza. Tunja: Universidad Pedagógica y Tecnológica de Colombia.

Toulmin, S. (1977). La comprensión bumana. Vol 1. El uso colectivo y la evolución de conceptos. Madrid: Alianza. 